\title{
Expansion of Power System Corridors Using Tier-1 Technique for Reactive Power Compensation
}

\author{
Ezennaya SO ${ }^{1 *}$, Ezechukwu OA ${ }^{1}$, Anierobi CC $^{1}$ and Akpe VA ${ }^{2}$ \\ ${ }^{1}$ Department of Electrical Engineering, Nnamdi Azikiwe University, Awka, Nigeria \\ ${ }^{2}$ Transmission Company of Nigeria (TCN)
}

\begin{abstract}
This paper develops a novel strategy for the expansion of the power system corridors for the release of the embedded transmission capacity. Both theoretical and practical network models are presented with a focus on power flow studies which concentrates on the steady state or static behavior of electrical power system. The methodology involves the power flow analysis revalidation of the existing standard IEEE 14 bus system and simulation using NewtonRaphson method in both MATLAB and Powerworld simulator (PWS) environment. This paper therefore establishes that an original designed network could be modified to take more loads without building new generators or transmission lines. The expansion of the existing IEEE 14 bus network to accommodatemore load involves the use of static compensators incorporated at the transmission lines. This technique is then analyzed extensively when distributed along the lines through the use of a distributed capacitors compensators, (DCC). DCC can affect significant change in power line impedance to improve the power transfer capacity of an interconnected power system. The application of the DCC on the line is the tier- 1 technique. The results obtained show that by applyingthe tier- 1 techniques to the transmission line, the system's capacity will remarkably improve and the transmission line will accept extra loading.
\end{abstract}

Keywords: Power corridors, Newton-Raphson, Static compensators, DCC, Tier-1 compensation

\section{Overview}

Electrical energy efficiency is of prime importance to industrial and commercial companies operating in today's competitive markets. Optimum use of power system components is one main concern that needs to be balanced with energy efficiency, for both economic and environmental reasons. Electricity plays a fundamental role in the economic development of any country. Every country seeks to ensure supply of electricity that is affordable, reliable and secure in order to sustain modern ways of living. The availability of electricity greatly facilitates industrialization. This is because, electricity is a convenient way to transport energy in which they are also converted into transmission, distribution, and consumption [1]. Investigations are done in this paper to see how capacitors distributed along the transmission lines can expand the transmission line corridor by the release of embedded transmission capacity.

During the past two decades, the increase in electrical energy demand has presented higher requirements from the power industry. In interconnected power systems, it has become important to fully utilize the existing transmission facilities in preference to building new power plants and transmission lines that are costly to implement and involving long construction times. This necessitated the need for alternative technology through the use of solid state electronic devices with fast response characteristics [2]. The requirement was fuelled by worldwide restructuring of electric utilities, increased environmental and efficiency regulations and difficulty in getting permit and right of ways for the construction of overhead power transmission lines. Different approaches such as reactive power compensation and phase shifting have been applied to increase the capacity, stability and security of the power system. This need in conjunction with the development of semiconductor thyristor switch opened the door for the development of flexible alternating current transmission system (FACTS) controllers [3]. FACTS controllers make it possible to control the voltage magnitude of a bus, active and reactive power flows through transmission line of a system.

\section{Power systems control}

Reactive power control service should satisfy the following system requirements [4];

1. Satisfy overall system and customer requirements for reactive energy on a continuous basis;

2. Maintaining system voltages within acceptable limits;

3. Provide a reserve to cover the changed reactive requirements caused by contingencies, against which the system is normally secured, and satisfy certain quality criteria in relation to speed of response;

\section{Optimize system losses.}

Three tiers could be established in reactive power control. These are tier-1, tier-2, and tier-3 controls. However, two or more of the three tiers can simultaneously be applied to form a hybrid tier control. A description of the three tiers of reactive power control could be made;

a. Tier-1 control co-ordinates the action of voltage and reactive power control devices within the transmission zones of the network in order to maintain the requisite voltage level at a certain node points in the system.

b. Tier-2 control involves a process of load optimization by improving load power factors which influence the distribution of

*Corresponding author: Ezennaya SO, Department of Electrical Engineering, Nnamdi Azikiwe University, Awka, Nigeria, Tel: +234 806049 2273; E-mail ezennayasamuel@gmail.com

Received July 13, 2015; Accepted December 25, 2015; Published January 01 2016

Citation: Ezennaya SO, Ezechukwu OA, Anierobi CC, Akpe VA (2016) Expansion of Power System Corridors Using Tier-1 Technique for Reactive Power Compensation. J Electr Electron Syst 5: 163. doi:10.4172/2332-0796.1000163

Copyright: ( 2016 Ezennaya SO, et al. This is an open-access article distributed under the terms of the Creative Commons Attribution License, which permits unrestricted use, distribution, and reproduction in any medium, provided the original author and source are credited. 
reactive power, where the system load is high, and the operator must be certain that, in case of a loss of generation, the remaining facilities will be able to deliver enough reactive power to keep the voltage within the required range. The same applies to the converse situation, where the system load is low and reactive power needs to be absorbed.

c. Tier-3 control is the generator control.

d. Hybrid-Tier control is the simultaneous application of both the tier-1, and tier-2 or tier-3. It can also involve the control at the three tier controls to the power system at the same time.

\section{Sources of reactive power}

Reactive power is produced or absorbed by all major components of a power system [4];

1. Generators

2. Power transfer components

3. Loads

4. Reactive power compensation devices

\section{Power Systems Reactive Power Compensation}

Reactive power compensation otherwise called reactive var compensation is the management of reactive power to improve the performance of AC power systems, maximizing stability by increasing flow of active power. Compensation can be carried out in series or in parallel (shunt). Series and shunt var compensation are used to modify the natural electrical characteristic of AC transmission or distribution system parameters as well as changes the equivalent impedance of the load.

1. devices for reactive power compensation

2. synchronous condensers

3. Flexible alternating current transmission system (FACTS) controllers.

4. the distributed capacitor compensation (DCC)

\section{The distributed capacitor compensation (Dcc) basis}

There are many different methods used for compensation in power systems. Some of these methods include reducing generator and transformer reactance, increasing the number of parallel lines used, using shunt capacitor compensators, or using series capacitor compensators [5].

DCC can be used in series or in parallel on a transmission line. The addition of DCC in series serves multiple purposes, the most important being the improvement in stability along the entire line. Its addition in parallel (shunt compensation) is used to support voltage at certain point on the line as opposed to the entire line and also inject or absorb reactive power to the loads. Series and Shunt compensation have been in use since the early part of the $20^{\text {th }}$ century. The first application of shunt compensation was in 1914 and has been used ever since becoming the most common method of capacitive compensation. Series compensation was first used in the United States for NY Power \& Light in 1928, but didn't become popular until the 1950's when the voltage levels that could be handled began increasing. By 1968, a 550 $\mathrm{kV}$ application had been implemented and today there are applications approaching $800 \mathrm{kV}[6]$.

The principal applications of DCC are;
- Improves voltage regulation

- Expand power transmission corridor of the transmission line

- Improves system stability

The applications previously mentioned are merely a selected few of the uses that DCC devices can provide. These applications and others are used throughout the world to improve the system as a whole. One common location where DCC devices are used heavily is on long transmission lines fed from hydroelectric generating plants. Many of the lines use the DCC devices to improve voltage regulation because the main load area is commonly several hundred kilometers from the generating station, allowing for large voltage decay.

\section{DCC circuit}

Capacitor compensator circuit is made up of the capacitor module and its protective scheme. The protective scheme shown in Figure 1 consists of [7];

1. A metal oxide varistor (MOV)

2. Current limiting damping equipment (CLDE)

3. Fast protective Device (FPD) and

4. By-pass switch (B)

The MOV has been designed to withstand the energy from external faults; faults appearing outside the series compensated circuit, without by-passing the DCC. The DCC module may be by-passed for any internal fault, (faults in the same circuit where the DCC is located). Each DCC is connected and disconnected from the line by means of two isolating disconnectors and one by-pass disconnector. The by-pass switch is of $\mathrm{Sf}_{6}$ type, with a spring operating mechanism.

The CLDE consists of a current limiting reactor, a resistor and a varistor in parallel with the reactor. The purpose of the resistor is to add damping to the capacitor discharge current, and thus quickly reduce the voltage across the capacitor after a by-pass operation. The varistor help to avoid fundamental frequency losses in the damping resistor during steady state operation.

The FPD scheme is based on a hermetically sealed and very fast high power switch, which replaces conventional spark gaps. The FPD works in combination with the MOV, and allows by-passing in a very controlled way in order to reduce the energy dissipated in the MOV.

\section{The Mathematical Model of Tier-1 Compensation}

Electrical power is transmitted through the transmission line from the sending-end of the line to the receiving-end of the line.

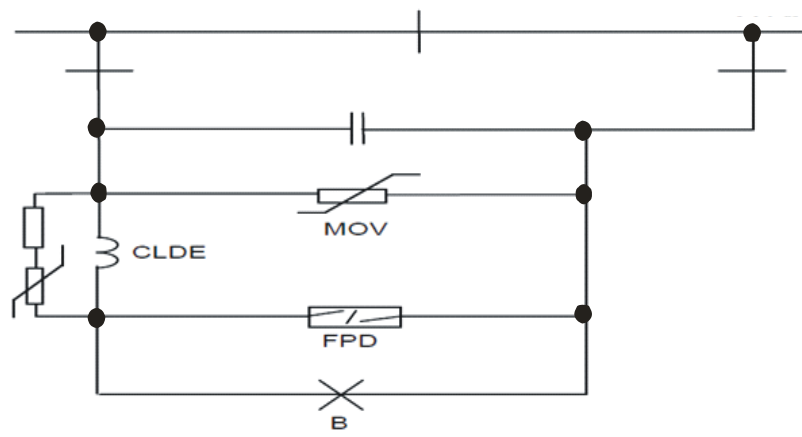

Figure 1: The single line diagram of a one-capacitor compensator in series. 
This can be analyzed through parameterization and modeling of the transmission line with passive components such as resistors, capacitors and inductors. The quantities of these parameters depend mostly on the line conductors and the physical or geometrical configuration of the lines. These conductors will have certain characteristics such as resistance and reactance both in series (from sending to receiving-ends of the line) and shunts (from the line to ground) associated with them.

\section{Basic principle of power in transmission}

Loads are more often expressed in terms of real (watts/KW) and reactive (vars/Kvars) power. It is convenient to deal with transmission line equations for the sending and receiving-end complex power and voltages $[8,9]$.

For a two-bus system shown in Figure 2, the sending and receivingend voltages are represented by the bus voltages while the sending end voltage leads the receiving end voltage by an angle, $\delta$. This angle is called the torque angle. The complex power leaving the receiving end and entering the sending-end of the transmission line can be expressed as

$$
S_{j}=P_{j}+j Q_{j}=V_{j} I_{j}^{*} \text { and } S_{i}=P_{i}+j Q_{i}=V_{i} I_{i}^{*}
$$

Where

$$
\begin{aligned}
& P_{j}=\frac{\left|V_{j}\right|\left|V_{i}\right|}{|Z|} \cos (\beta-\delta)-\frac{\left|V_{j}\right|^{2}}{|Z|} \cos (\beta) \text { And } \\
& Q_{j}=\frac{\left|V_{j}\right|\left|V_{i}\right|}{|Z|} \sin (\beta-\delta)-\frac{\left|V_{j}\right|^{2}}{|Z|} \sin (\beta)
\end{aligned}
$$

Similarly,

$$
\begin{aligned}
& P_{i}=\left|\frac{1}{Z}\right|\left|V_{i}\right|^{2} \cos (\beta)-\mid \frac{\left|V_{i}\right|\left|V_{j}\right|}{|Z|} \cos (\beta+\delta) \\
& Q_{i}=\left.\left|\frac{1}{Z}\right| V_{i}\right|^{2} \sin (\beta)-\mid \frac{\left|V_{i}\right|\left|V_{j}\right|}{|Z|} \sin (\beta+\delta)
\end{aligned}
$$

At $\delta=\beta$, the maximum power delivered at the load will be;

$$
\begin{gathered}
P_{j}=\frac{\left|V_{j}\right|\left|V_{i}\right|}{|Z|}-\frac{\left|V_{j}\right|^{2}}{|Z|} \cos (\beta) ; \\
\text { If, } \beta=\theta \text {, then } \cos \theta=\frac{R}{|Z|}
\end{gathered}
$$

But the resistance $R$ of a transmission line is very small compared to its reactance, so that;

$$
\theta=\tan ^{-1}\left(\frac{X}{R}\right) \approx 90^{\circ}
$$

Where $Z=R+j X$ and $\theta=\delta$.

Therefore the receiving-end power $\left(P_{j}\right)$ becomes;

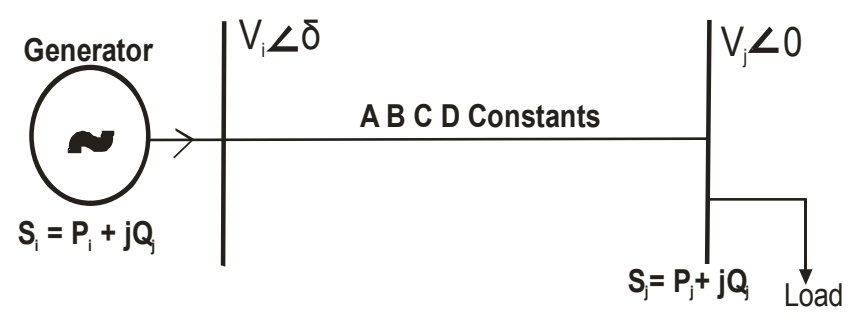

Figure 2: A two bus system

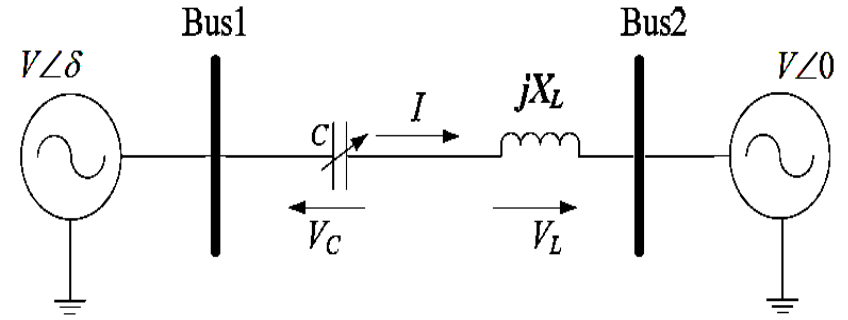

Figure 3: A simplified model of transmission system with series compensation.

$$
P_{j}=\frac{\left|V_{j}\right|\left|V_{i}\right|}{|X|} \sin (\delta) \text { and } Q_{j}=\frac{\left|V_{j}\right|\left|V_{i}\right|}{|X|} \cos (\delta)-\frac{\left|V_{j}\right|^{2}}{|X|}
$$

Hence $Z \approx j X$.

For a very small value of $\delta, \cos \delta=1$ thus;

$Q_{j}=\frac{\left|V_{j}\right|}{|X|}\left(\left|V_{i}\right|-\left|V_{j}\right|\right)$

where $\left(\left|V_{i}\right|-\left|V_{j}\right|\right)=|\Delta V|$

$|\Delta V|$ is called the magnitude of voltage drop across the transmission line.

Therefore;

$Q_{j}=\frac{\left|V_{j}\right|}{|X|}|\Delta V|$

\section{Reactive Power compensation of transmission lines}

Equations (8) through (11) indicate that the active and reactive power/current flow can be regulated by controlling the voltages, phase angles and line impedances of the transmission system. It has been shown above that the active power flow will reach the maximum when angle $\delta$ is $90^{\circ}$.

Series Compensation of A Transmission Line: A series-connected capacitor adds a voltage in opposition to the transmission line voltage drop, therefore reducing the series line impedance.

Figure 3 show a simplified model of a transmission system with series compensation. The voltage magnitude of the sending-end is assumed equal as $|\boldsymbol{V}|$, and the phase angle between them is $\delta$. The transmission line is assumed lossless and represented by the reactance $\boldsymbol{X}_{\boldsymbol{L}}$. A control capacitor is series-connected in the transmission line with voltage addition $V_{i n j^{*}}$

The Degree Of Series Compensation (Ks): The degree of series compensation or percentage compensation $(\boldsymbol{K})$ is used to analyze a transmission line with the required addition of series capacitor. It is defined as the fraction of $\boldsymbol{X}$, which refers to the total capacitive reactance of series compensators and $X_{L}$, which refers to the total inductive reactance of the line, as defined in equation 12;

$$
K_{s}=\frac{X_{c}}{X_{L}}
$$

Therefore, the capacitance, $\mathrm{C}$ as a portion of the line react $X_{c}^{(n)}=X_{c}^{(n-1)}+\left(\frac{\vartheta X_{c}}{X_{c}}\right)^{(n)} X_{c}^{(n-1)}$ ance can be obtained from 
$X_{c}=K_{s} X_{L}$

and

$C=\frac{1}{2 \pi f X_{c}}$

The overall series reactance, $\mathrm{X}$ of the transmission line is;

$X=X_{L}-X_{c}=\left(1-K_{s}\right) X_{L}$

Thus the active power transmitted becomes;

$P_{i}=P_{j}=\frac{|V|^{2}}{\left(1-K_{s}\right) X_{L}} \sin \delta$

The reactive power supplied by the capacitor is calculated as;

$Q_{c}=2 \frac{|V|^{2} K_{s}}{X_{L}\left(1-K_{s}\right)^{2}}(1-\cos \delta)$

From the above equation, it can be seen that transmitted active power increases with Ks [10].

\section{Effective line reactance with and without dcc device}

Figure 4 shows a simple transmission line without a compensating device. Equation (18) is the effective line reactance in matrix form.

$X_{e f f}=\left[\begin{array}{ll}A & B \\ C & D\end{array}\right]$

Where $X_{\text {eff }}$ is the effective reactance of the line.

The power flow equation becomes

$\left[\begin{array}{c}V_{i} \\ I_{i}\end{array}\right]=\left[\begin{array}{ll}A & B \\ C & D\end{array}\right]\left[\begin{array}{c}V_{j} \\ I_{j}\end{array}\right]$

Inserting a single series capacitor device on the line as in Figure 4 changes the $\mathrm{ABCD}$ parameters and the effective reactance of the line becomes (Figure 5)

$$
X_{\text {eff }}=\left[\begin{array}{cc}
A_{1 / 2} & B_{1 / 2} \\
C_{1 / 2} & D_{1 / 2}
\end{array}\right] *\left[\begin{array}{cc}
1 & X_{c} \\
0 & 1
\end{array}\right] *\left[\begin{array}{cc}
A_{1 / 2} & B_{1 / 2} \\
C_{1 / 2} & D_{1 / 2}
\end{array}\right]
$$

As the power flow equation changes to;

$$
\left[\begin{array}{c}
V_{i} \\
I_{i}
\end{array}\right]=\left[\begin{array}{cc}
A_{1 / 2} & B_{1 / 2} \\
C_{1 / 2} & D_{1 / 2}
\end{array}\right] *\left[\begin{array}{cc}
1 & X_{c} \\
0 & 1
\end{array}\right] *\left[\begin{array}{cc}
A_{1 / 2} & B_{1 / 2} \\
C_{1 / 2} & D_{1 / 2}
\end{array}\right]\left[\begin{array}{c}
V_{j} \\
I_{j}
\end{array}\right]
$$

The ABCD parameters are halved because the DCC is place at exactly midpoint (Figure 6) to the length of the line hence one DCC device is used.

Inserting several series capacitor devices on the line will change

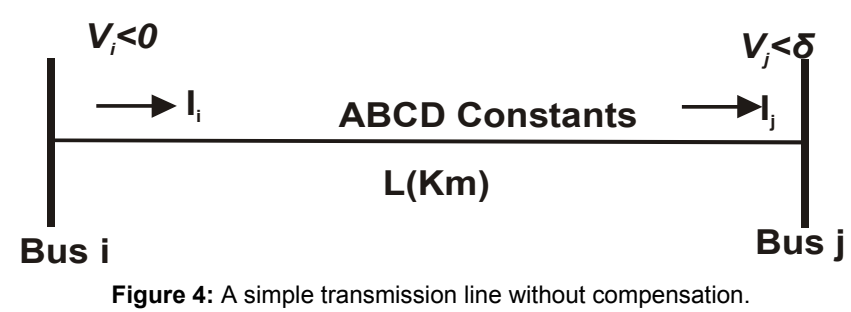

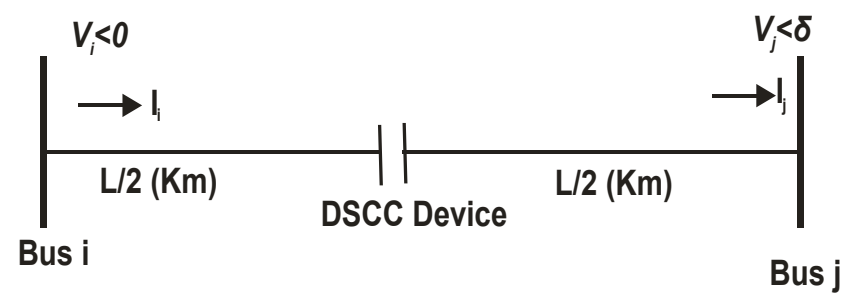

Figure 5: A transmission line with single DCC device (compensated line).

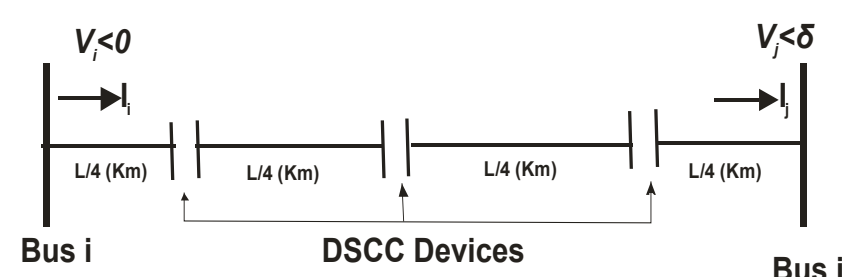

Figure 6: A transmission line with multiple DCC devices

the $A B C D$ parameters hence the more the capacitors on the line are distributed, the better the performance. Figure 6 shows a transmission line with multiple series capacitor devices and equation 21 changes to;

$$
X_{e f f}=\left[\begin{array}{cc}
A_{1 / 4} & B_{1 / 4} \\
C_{1 / 4} & D_{1 / 4}
\end{array}\right] *\left[\begin{array}{cc}
1 & X_{c} \\
0 & 1
\end{array}\right] *\left[\begin{array}{cc}
A_{1 / 4} & B_{1 / 4} \\
C_{1 / 4} & D_{1 / 4}
\end{array}\right] *\left[\begin{array}{cc}
1 & X_{c} \\
0 & 1
\end{array}\right] *\left[\begin{array}{cc}
A_{1 / 4} & B_{1 / 4} \\
C_{1 / 4} & D_{1 / 4}
\end{array}\right] *\left[\begin{array}{cc}
1 & X_{c} \\
0 & 1
\end{array}\right] *\left[\begin{array}{cc}
A_{1 / 4} & B_{1 / 4} \\
C_{1 / 4} & D_{1 / 4}
\end{array}\right] *\left[\begin{array}{cc}
1 & X_{c} \\
0 & 1
\end{array}\right]
$$

The ABCD constants are divided by four (Figure 6) when the DCC is placed at quarter of the line hence three Capacitors are used and placed at every quarter of the line.

\section{Power flow including dec in matrix forms}

From equation (21), the transfer admittance matrix of the DCC is given by [11];

$$
\left[\begin{array}{c}
I_{i} \\
I_{j}
\end{array}\right]=\left[\begin{array}{ll}
j B_{i i} & j B_{i j} \\
j B_{j i} & j B_{j j}
\end{array}\right] *\left[\begin{array}{c}
I_{i} \\
I_{j}
\end{array}\right]
$$

Where

$$
B_{i i}=B_{j j}=\frac{-1}{X_{c}}, B_{j i}=B_{i j}=\frac{1}{X_{c}}
$$

Equation (23) holds for inductive operation while for capacitive operation, the sign are reversed. The active and reactive power equations at bus $\boldsymbol{j}$ are as in equations (25) and (26) below;

$$
\begin{aligned}
& P_{j}=V_{j} V_{i} B_{i j} \sin \left(\delta_{j}-\delta_{i}\right) \\
& Q_{i}=-V_{j}^{2} B_{j j}-V_{j} V_{i} B_{i j} \cos \left(\delta_{j}-\delta_{i}\right)
\end{aligned}
$$

In Newton-Raphson solutions, these equations are linearized with respect to the series reactance. For the condition shown in Figure 3 where series reactance regulates the amount of active power flowing from bus $\boldsymbol{i}$ to $\boldsymbol{j}$ at a value $\boldsymbol{P}$, [11] the set of linearized power equation is,

$$
\left[\begin{array}{l}
\Delta P_{i} \\
\Delta P_{j} \\
\Delta Q_{j} \\
\Delta P^{X_{c}}
\end{array}\right]=\left[\begin{array}{ccccc}
\frac{\partial P_{i}}{\partial \theta_{i}} & \frac{\partial P_{i}}{\partial \theta_{i}} & \frac{\partial P_{i} V_{i}}{\partial V_{i}} & \frac{\partial P_{i} V_{j}}{\partial V_{j}} & \frac{\partial P_{i} X_{c}}{\partial V_{i}} \\
\frac{\partial P_{j}}{\partial \delta_{i}} & \frac{\partial P_{j}}{\partial \delta_{j}} & \frac{\partial P_{j} V_{i}}{\partial V_{i}} & \frac{\partial P_{j} V_{j}}{\partial V_{i}} & \frac{\partial Q_{c} X_{c}}{\partial X_{c}} \\
\frac{\partial Q_{i}}{\partial \delta_{i}} & \frac{\partial Q_{i}}{\partial \delta_{j}} & \frac{\partial Q_{i} V_{i}}{\partial V_{i}} & \frac{\partial Q_{j} V_{j}}{\partial V_{j}} & \frac{\partial Q_{j} X_{c}}{\partial X_{c}} \\
\frac{\partial P_{i j}^{X c}}{\partial \delta_{i}} & \frac{\partial P_{i j}^{X c}}{\partial \delta_{i}} & \frac{\partial P_{i j}^{X c}}{\partial V_{i}} & \frac{\partial P_{i j}^{X c}}{\partial V_{j}} & \frac{\partial P_{i j}^{X_{c}}}{\partial \delta_{i}}
\end{array}\right]\left[\begin{array}{c}
\frac{\Delta \delta_{i}}{V_{i}} \\
\frac{\Delta V_{j}}{V j} \\
\frac{\Delta X_{c}}{X_{c}}
\end{array}\right]
$$




$$
\Delta P_{i j}^{X_{c}}=P_{i j}^{\text {reg. }}-P_{i j}^{X_{c} \text { cal. }}
$$

Where, $\Delta P_{i j}^{X_{c}}$ is the active power flow mismatch for the series reactance calculated;

$$
\Delta X_{c}=X_{c}^{(n)}-X_{c}^{(n-1)}
$$

$\Delta X_{c}$ is the incremental change in series reactance; and $P_{i j}^{X_{c} \text { cal. is }}$ the calculated power given by equation (25). The state variable $X_{c}$ of the DCC controller is updated at the end of each iterative step according to equation (30);

$$
X_{c}^{(n)}=X_{c}^{(n-1)}+\left(\frac{X_{c}}{X_{c}}\right)^{(n)} X_{c}^{(n-1)}
$$

\section{The Standard IEEE 14 Bus Test Systems (Revalidation)}

One of the international load flow test systems is the IEEE14 bus system. Load flow analysis is carried out in IEEE 14 bus test system. Figure 7 show the standard IEEE 14 bus network simulated in Powerworld platform. The run mode of Power world simulator enable the simulation of the existing IEEE 14 bus test system model using N-R iterative method to obtain the bus voltages, phase angles, line losses, real and reactive power flows. The system topology consists of 14 buses, 20 transmission lines or branches, 2 online generators, 3 online synchronous compensators used only for reactive power support, and 11 loads totaling $259 \mathrm{MW}$ and 78.7 Mvar.

The simulated result of the test system in Power world shown in
Table 1 gives a very close result when compared with the MATLAB results of Table 2. It was therefore confirmed that the result obtained when DCC is applied on the IEEE 14 bus network using only Power world simulation software due to its flexibility and simplicity.

Using codes written in MATLAB and system information exported from Power world simulator, the standard IEEE 14 bus network is revalidated and reconfirmed.

\section{Simulation result}

The revalidated Standard IEEE 14 bus network shows that the total real and reactive power loss of the system are 15.31 MW and 36.77 Mvar respectively with the systems maximum current rating totaling 2948.91 Amps. As a result, the system's maximum MVA loading becomes 696.604 MVA. These results confirmed and agreed with the standard performance of the standard IEEE 14 bus system as shown in Tables 1 and 2 (Power world simulator tool) and Table 2 (MATLAB simulator tool). All bus voltages were also confirmed to fall within the recommended limit $(0.9 \leq V \leq 1.1$ p.u).

Total power loss in Powerworld simulator: 15.31 MW and 36.77 Mvar

The Table 3 confirmed that the standard IEEE 14 bus system total power loss in Powerworld simulator is 15.31 MW and 36.77 Mvar and that of MATLAB is $15.031 \mathrm{MW}$ and $35.348 \mathrm{Mvar}$. This is a clear indication that the software tool used for this model is validated.

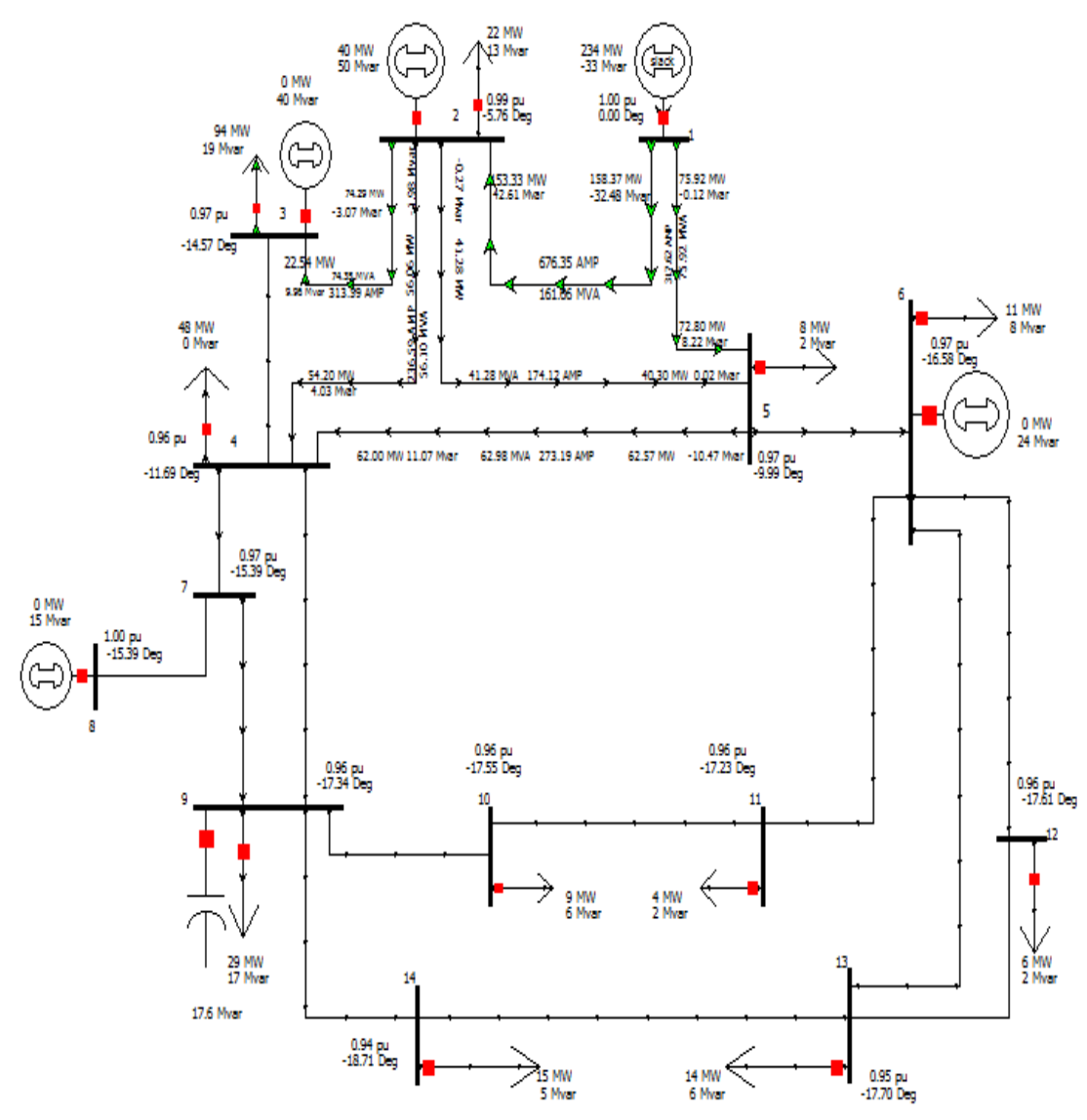

Figure 7: Standard IEEE 14 bus test system in Powerworld simulator environment. 
Citation: Ezennaya SO, Ezechukwu OA, Anierobi CC, Akpe VA (2016) Expansion of Power System Corridors Using Tier-1 Technique for Reactive Power Compensation. J Electr Electron Syst 5: 163. doi:10.4172/2332-0796.1000163

Page 6 of 10

\begin{tabular}{|c|c|c|c|c|c|c|c|c|c|c|c|c|c|c|c|}
\hline \multicolumn{2}{|c|}{ Line records } & \multirow{2}{*}{$\begin{array}{l}\text { MW } \\
\text { From }\end{array}$} & \multirow[t]{2}{*}{ MW To } & \multirow[t]{2}{*}{ Max MW } & \multirow{2}{*}{$\begin{array}{l}\text { Mvar } \\
\text { From }\end{array}$} & \multirow[t]{2}{*}{ Mvar To } & \multirow[t]{2}{*}{ Max Mvar } & \multirow{2}{*}{$\begin{array}{l}\text { MVA } \\
\text { From }\end{array}$} & \multirow[t]{2}{*}{ MVA To } & \multirow[t]{2}{*}{ Max MVA } & \multirow{2}{*}{$\begin{array}{l}\text { Amps } \\
\text { From }\end{array}$} & \multirow[t]{2}{*}{ Amps To } & \multirow{2}{*}{$\begin{array}{c}\operatorname{Max} \\
\text { Amps }\end{array}$} & \multirow{2}{*}{$\begin{array}{l}\text { MW } \\
\text { Loss }\end{array}$} & \multirow{2}{*}{$\begin{array}{l}\text { Mvar } \\
\text { Loss }\end{array}$} \\
\hline $\begin{array}{l}\text { From } \\
\text { NO }\end{array}$ & $\begin{array}{l}\text { To } \\
\text { NO }\end{array}$ & & & & & & & & & & & & & & \\
\hline 1 & 2 & 158.4 & 153.333 & 158.366 & -32.5 & 42.612 & 42.612 & 161.7 & 159.144 & 161.633 & 676.35 & 671.202 & 676.35 & 5.03 & 10.13 \\
\hline 1 & 5 & 75.9 & -72.8 & 75.917 & -0.1 & 8.218 & 8.212 & 75.9 & 73.263 & 75.917 & 317.615 & 316.494 & 317.615 & 3.12 & 8.1 \\
\hline 2 & 3 & 74.3 & -71.654 & 74.289 & -3.1 & 9.958 & 9.958 & 74.4 & 72.342 & 74.353 & 313.588 & 311.998 & 313.588 & 2.64 & 6.89 \\
\hline 2 & 4 & 56.1 & -54.205 & 56.061 & -2.0 & 4.028 & 4.028 & 56.1 & 54.354 & 56.096 & 236.587 & 235.762 & 236.587 & 1.86 & 2.05 \\
\hline 2 & 5 & 41.3 & -40.295 & 41.283 & -0.3 & 0.015 & 0.268 & 41.3 & 40.295 & 41.283 & 174.116 & 174.074 & 174.116 & 0.99 & -0.25 \\
\hline 3 & 4 & -22.5 & 23.019 & 23.019 & 11.0 & -13.064 & 13.064 & 25.1 & 26.468 & 26.468 & 105.256 & 114.804 & 114.804 & 0.48 & -2.02 \\
\hline 4 & 5 & -62 & 62.574 & 62.574 & 11.1 & -10.468 & 11.074 & 63 & 63.443 & 63.443 & 273.192 & 274.074 & 274.074 & 0.57 & 0.61 \\
\hline 4 & 7 & 29 & -28.962 & 28.962 & -3.1 & 5.033 & 5.033 & 29.1 & 29.396 & 29.396 & 126.351 & 126.351 & 126.351 & 0.00 & 1.91 \\
\hline 4 & 9 & 16.4 & -16.431 & 16.431 & 1.1 & 0.534 & 1.087 & 16.5 & 16.439 & 16.466 & 71.424 & 71.424 & 71.424 & 0.00 & 1.62 \\
\hline 5 & 6 & 42.9 & -42.922 & 42.922 & 0.6 & 4.317 & 4.317 & 42.9 & 43.139 & 43.139 & 185.444 & 185.444 & 185.444 & 0.00 & 4.95 \\
\hline 6 & 11 & 6.6 & -6.584 & 6.636 & 2.8 & -2.707 & 2.816 & 7.2 & 7.118 & 7.209 & 30.988 & 30.988 & 30.998 & 0.05 & 0.11 \\
\hline 6 & 12 & 7.7 & -7.604 & 7.688 & 2.5 & -2.278 & 2.454 & 8.1 & 7.938 & 8.07 & 34.693 & 34.693 & 34.693 & 0.08 & 0.18 \\
\hline 6 & 13 & 17.4 & -17.156 & 17.401 & 6.9 & -6.429 & 6.911 & 18.7 & 18.322 & 18.724 & 80.488 & 80.488 & 80.488 & 0.24 & 0.48 \\
\hline 7 & 8 & 0 & -0.006 & 0.006 & -14.7 & 15.132 & 15.132 & 14.7 & 15.132 & 15.132 & 63.308 & 63.308 & 63.308 & 0.00 & 0.4 \\
\hline 7 & 9 & 29 & -28.956 & 28.956 & 9.7 & -8.613 & 9.695 & 30.5 & 30.21 & 30.536 & 131.253 & 131.253 & 131.253 & 0.00 & 1.08 \\
\hline 9 & 10 & 5.9 & -5.922 & 5.943 & 5.0 & -4.911 & 4.966 & 7.7 & 7.694 & 7.745 & 33.649 & 33.649 & 33.649 & 0.02 & 0.05 \\
\hline 9 & 14 & 10 & -9.973 & 9.953 & 4.1 & -3.8 & 4.139 & 10.8 & 10.505 & 10.779 & 46.831 & 13.996 & 13.996 & 0.16 & 0.34 \\
\hline 10 & 11 & -3.1 & 3.084 & 3.084 & -0.9 & 0.907 & 0.907 & 3.2 & 3.215 & 3.215 & 13.996 & 7.215 & 7.251 & 0.01 & 0.02 \\
\hline 12 & 13 & 1.5 & -1.498 & 1.504 & 0.7 & -0.673 & 0.679 & 1.7 & 1.642 & 1.651 & 7.251 & 23.336 & 23.366 & 0.01 & 0.01 \\
\hline 13 & 14 & 5.2 & -5.103 & 5.156 & 1.3 & -1.197 & 1.305 & 5.3 & 5.241 & 5.319 & 23.336 & 23.336 & 23.336 & 0.05 & 0.11 \\
\hline \multicolumn{2}{|c|}{ Total } & 490 & 474.547 & 666.151 & 0.1 & 36.614 & 148.663 & 693.3 & 685.3 & 696.604 & 2948.71 & 2947.414 & 2956.14 & 15.31 & 36.77 \\
\hline
\end{tabular}

Table 1: Line records of the standard IEEE 14 bus system in Power world simulator.15.31-0.25.

\begin{tabular}{|c|c|c|c|c|c|c|c|c|c|c|}
\hline Number & Name & Nom kV & PU Volt & Volt (kV) & Angle (Deg) & Load MW & Load Mvar & Gen MW & Gen Mvar & s.sht Mvar \\
\hline 1 & 1 & 138 & 1.00000 & 138.00 & 0.00 & & & 234.28 & -32.6 \\
\hline 2 & 2 & 138 & 0.99197 & 136.892 & -5.76 & 21.7 & 12.7 & 40 & 50 \\
\hline 3 & 3 & 138 & 0.97006 & 133.869 & -14.57 & 94.2 & 19 & 0 & 40 \\
\hline 4 & 4 & 138 & 0.96454 & 133.107 & -11.69 & 47.8 & 0 & & \\
\hline 5 & 5 & 138 & 0.96845 & 133.646 & -9.99 & 7.6 & 1.6 & & \\
\hline 6 & 6 & 138 & 0.97323 & 134.306 & -16.58 & 11.2 & 7.5 & 0 & 24 \\
\hline 7 & 7 & 138 & 0.97334 & 134.322 & -15.39 & & & & \\
\hline 8 & 8 & 138 & 1.00000 & 138.000 & -15.39 & & & 0 & 15.13 \\
\hline 9 & 9 & 138 & 0.96294 & 132.886 & -17.34 & 29.5 & 16.6 & & \\
\hline 10 & 10 & 138 & 0.95663 & 132.015 & -17.55 & 9 & 5.8 & & \\
\hline 11 & 11 & 138 & 0.96106 & 132.626 & -17.23 & 3.5 & 1.8 & & \\
\hline 12 & 12 & 138 & 0.95722 & 132.097 & -17.61 & 6.1 & 1.6 & & \\
\hline 13 & 13 & 138 & 0.95233 & 132.422 & -17.7 & 13.5 & 5.8 & & \\
\hline 14 & 14 & 138 & 0.93845 & 129.507 & -18.71 & 14.9 & 5 & & \\
\hline
\end{tabular}

Table 2: Bus records of IEEE 14 bus system in Powerworld simulator.

Case 1: Modification of the ieee 14 bus network (addition of an excess load to the network)

To illustrate that an already saturated network can be expanded by the use of capacitors distributed along the lines at strategic places, an existing load of a selected Company in Nigeria was used - the General Steel Mills (GSM), Asaba. The Company's total maximum active and reactive power demand are 17.80 MW and 25.71 Mvar respectively [12]. These loads were added to bus 6 of the standard IEEE 14 bus system which modified the revalidated results of the system. The active and reactive power losses increased from the normal operating performance of the 14 bus standard network to $59.85 \mathrm{MW}$ and 226.84 Mvar respectively. The system's maximum amperage was $\mathbf{5 6 5 8 . 2 8 7}$ Amps as all the bus voltages dropped below 0.9 p.u except the slack bus-bus 1 (Table 4). The MVA maximum loading also increased to 1062.225 MVA (Overloading). For these reasons, it is enough to say 
Citation: Ezennaya SO, Ezechukwu OA, Anierobi CC, Akpe VA (2016) Expansion of Power System Corridors Using Tier-1 Technique for Reactive Power Compensation. J Electr Electron Syst 5: 163. doi:10.4172/2332-0796.1000163

Page 7 of 10

\begin{tabular}{|c|c|c|c|c|c|c|c|}
\hline \multirow{2}{*}{ Bus No. } & \multicolumn{2}{|c|}{ Bus Voltage } & \multicolumn{2}{c|}{ Load } & \multicolumn{2}{c|}{ Generation } & Injected Mvar \\
\cline { 2 - 8 } & Magnitude & Angle & MW & MVAR & MW & MVAR \\
\hline 1 & 1.050 & 0 & 0 & 0 & 234.029 & 61.659 \\
\hline 2 & 1.000 & -4.664 & 21.7 & 12.7 & 40 & -11.307 & 0 \\
\hline 3 & 0.970 & -13.283 & 94.2 & 19 & 0 & 36.233 & 0 \\
\hline 4 & 0.964 & -10.372 & 47.8 & 0 & 0 & 0 \\
\hline 5 & 0.970 & -8.79 & 7.6 & 1.6 & 0 & 0 \\
\hline 6 & 1.000 & -15.109 & 11.2 & 7.5 & 0 & 0 \\
\hline 7 & 0.979 & -13.768 & 0 & 0 & 0 & 0 \\
\hline 8 & 1.000 & -13.768 & 0 & 0 & 0 & 0 \\
\hline 9 & 0.963 & -15.594 & 29.5 & 16.6 & 0 & 0 \\
\hline 10 & 0.962 & -15.835 & 9 & 5.8 & 0 & 0 \\
\hline 11 & 0.977 & -15.608 & 3.5 & 1.8 & 0 & 0 \\
\hline 12 & 0.982 & -16.085 & 6.1 & 1.6 & 0 & 0 \\
\hline 13 & 0.976 & -16.134 & 13.5 & 5.8 & 0 & 0 \\
\hline 14 & 0.949 & -17.014 & 14.9 & 5 & 0 & 0 \\
\hline
\end{tabular}

Table 3: The bus records of the IEEE 14 bus system in MATLAB tool.

\begin{tabular}{|c|c|c|c|c|c|c|c|c|c|c|}
\hline \multicolumn{2}{|c|}{ Bus records } & Nom kV & PU Volt & Volt (kV) & Angle (Deg) & Load MW & Load MVar & Gen MW & Gen MVar & s.shnts Mvar \\
\hline NO & Name & & & & & & & & \\
\hline 1 & 1 & 138 & 1 & 138 & 0 & & & 256.71 & 371.82 \\
\hline 2 & 2 & 138 & 0.82572 & 113.95 & -4.21 & 21.7 & 12.7 & 40 & 50 \\
\hline 3 & 3 & 138 & 0.62455 & 83.188 & -17.9 & 91.53 & 19.72 & 0 & 0 \\
\hline 4 & 4 & 138 & 0.59434 & 82.018 & -10.26 & 45.16 & 113.38 & & \\
\hline 5 & 5 & 138 & 0.6584 & 90.859 & -8.27 & 7.53 & 1.59 & & \\
\hline 6 & 6 & 138 & 0.48283 & 66.63 & -24.44 & 13.9 & 20.07 & 0 & 0 \\
\hline 7 & 7 & 138 & 0.51624 & 71.241 & -19.52 & & & & \\
\hline 8 & 8 & 138 & 0.51624 & 71.241 & -25.52 & & & 0 & \\
\hline 9 & 9 & 138 & 0.48187 & 66.497 & -26.41 & 22.98 & 12.53 & & \\
\hline 10 & 10 & 138 & 0.4696 & 66.804 & -25.93 & 6.8 & 4.38 & & \\
\hline 11 & 11 & 138 & 0.47045 & 64.923 & -27.46 & 2.65 & 1.36 & & \\
\hline 12 & 12 & 138 & 0.45884 & 63.32 & -27.67 & 4.48 & 1.18 & & \\
\hline 13 & 13 & 138 & 0.45279 & 62.486 & -27.67 & 9.75 & 4.19 & & \\
\hline 14 & 14 & 138 & 0.43901 & 6.583 & -30.11 & 10.35 & 3.47 & & \\
\hline
\end{tabular}

Table 4: Bus records of the modified standard IEEE 14 bus network (with $17.80 \mathrm{MW}$ and 25.71 Mvar extra load addition).

\begin{tabular}{|c|c|c|c|c|c|c|c|c|c|c|c|c|c|c|c|}
\hline \multicolumn{2}{|c|}{ Line Records } & $\begin{array}{l}\text { MW } \\
\text { From }\end{array}$ & MW To & Max MW & $\begin{array}{l}\text { Mvar } \\
\text { from }\end{array}$ & Mvar To & $\begin{array}{l}\text { Max } \\
\text { Mvar }\end{array}$ & $\begin{array}{l}\text { MVA } \\
\text { From }\end{array}$ & MVA To & $\begin{array}{l}\text { Max } \\
\text { MVA }\end{array}$ & $\begin{array}{l}\text { Amps } \\
\text { From }\end{array}$ & Amps To & $\begin{array}{l}\text { Max } \\
\text { Amps }\end{array}$ & MW loss & $\begin{array}{l}\text { Mvar } \\
\text { loss }\end{array}$ \\
\hline 1 & 2 & 180.8 & 163.425 & 180.84 & 236.4 & 187.704 & 236.434 & 297.7 & 248.879 & 297.665 & 1234.34 & 1260.995 & 1260.995 & 17.41 & 48.73 \\
\hline 1 & 5 & 75.9 & -62.494 & 75.872 & 135.4 & -83.694 & 135.39 & 155.2 & 104.452 & 155.2 & 649.309 & 663.723 & 663.723 & 13.38 & 51.7 \\
\hline 2 & 3 & 78.9 & -70.943 & 78.86 & 71.1 & -40.085 & 71.092 & 106.2 & 81.485 & 106.74 & 537.953 & 545.84 & 545.84 & 7.92 & 32.01 \\
\hline 2 & 4 & 59.1 & -49.186 & 59.135 & 89.1 & -60.896 & 89.147 & 107 & 78.279 & 106.978 & 542.024 & 551.028 & 551.028 & 9.95 & 28.25 \\
\hline 2 & 5 & 43.7 & -38.501 & 43.728 & 64.8 & -50.701 & 64.764 & 78.1 & 63.662 & 78.144 & 395.932 & 404.532 & 404.532 & 5.23 & 14.06 \\
\hline 3 & 4 & -20.6 & 22.075 & 22.075 & 20.4 & -17.848 & 20.36 & 29 & 28.338 & 28.953 & 193.949 & 199.83 & 199.83 & 1.49 & 2.51 \\
\hline 4 & 5 & -55.2 & 58.335 & 58.335 & -72.6 & 81.951 & 81.951 & 91.2 & 100.593 & 100.593 & 641.907 & 639.204 & 641.907 & 3.13 & 9.37 \\
\hline 4 & 7 & 23.6 & 23.608 & 23.608 & 24.1 & -17.367 & 24.107 & 33.7 & 29.308 & 33.741 & 237.514 & 237.514 & 237.514 & 0.00 & 6.74 \\
\hline 4 & 9 & 13.5 & -13.546 & 13.546 & 13.8 & -7.931 & 13.832 & 19.4 & 15.697 & 19.36 & 137.283 & 136.283 & 136.283 & 0.00 & 5.9 \\
\hline 5 & 6 & 35.1 & -35.126 & 35.126 & 50.9 & -28.647 & 50.857 & 61.8 & 45.326 & 61.108 & 392.751 & 392.751 & 392.751 & 0.00 & 22.21 \\
\hline 6 & 11 & 3.6 & -3.543 & 3.603 & 1.3 & -1.196 & 1.322 & 3.8 & 3.74 & 3.838 & 33.258 & 33.258 & 33.258 & 0.06 & 0.13 \\
\hline 6 & 12 & 5.5 & -5.339 & 5.521 & 2 & -1.617 & 1.995 & 5.9 & 5.579 & 5.87 & 50.866 & 50.866 & 50.866 & 0.18 & 0.38 \\
\hline 6 & 13 & 12.1 & -11.607 & 12.101 & 5.3 & -4.28 & 5.252 & 13.2 & 12.371 & 13.192 & 114.305 & 114.305 & 114.305 & 0.49 & 0.97 \\
\hline 7 & 8 & 0 & 0 & 0 & 0 & 0 & 0 & 0 & 0 & 0 & 0 & 0 & 0 & 0 & 0 \\
\hline 7 & 9 & 23.6 & -23.608 & 23.608 & 17.4 & -13.822 & 17.367 & 29.3 & 27.356 & 29.308 & 237.514 & 237.514 & 237.514 & 0.00 & 3.55 \\
\hline 9 & 10 & 6 & -5.914 & 5.995 & 4.8 & -4.558 & 4.772 & 7.7 & 7.467 & 7.662 & 66.525 & 66.525 & 66.525 & 0.08 & 0.21 \\
\hline 9 & 14 & 8.2 & -7.718 & 8.174 & 4 & -3.078 & 4.047 & 9.1 & 8.31 & 9.121 & 79.189 & 79.189 & 79.189 & 0.45 & 0.97 \\
\hline 10 & 11 & -0.9 & -0.892 & 0.892 & 0.2 & -0.167 & 0.175 & 0.9 & 0.908 & 0.908 & 8.071 & 8.071 & 8.071 & 0.00 & 0.01 \\
\hline 12 & 13 & 0.9 & -0.847 & 0.856 & 0.4 & -0.433 & 0.442 & 1 & 0.951 & 0.964 & 8.786 & 8.786 & 8.786 & 0.01 & 0.01 \\
\hline 13 & 14 & 2.7 & -2.633 & 2.696 & 0.5 & -0.393 & 0.521 & 2.7 & 2.662 & 2.746 & 25.37 & 25.37 & 25.37 & 0.06 & 0.13 \\
\hline \multicolumn{2}{|l|}{ Total } & 496.5 & 436.736 & 654.571 & 669.3 & 442.466 & 823.827 & 1052.9 & 865.413 & 1062.25 & 5596.846 & 5655.584 & 5658.287 & 59.85 & 226.84 \\
\hline
\end{tabular}

Table 5: Line records of the modified standard IEEE 14 bus network (with $\mathbf{1 7 . 8 0}$ MW and 25.71 Mvar extra load addition). 
Citation: Ezennaya SO, Ezechukwu OA, Anierobi CC, Akpe VA (2016) Expansion of Power System Corridors Using Tier-1 Technique for Reactive Power Compensation. J Electr Electron Syst 5: 163. doi:10.4172/2332-0796.1000163

Page 8 of 10

\begin{tabular}{|c|c|c|c|c|c|c|c|c|c|c|}
\hline \multicolumn{2}{|c|}{ Bus records } & \multirow[t]{2}{*}{ Nom kV } & \multirow[t]{2}{*}{ PU Volt } & \multirow[t]{2}{*}{ Volt (kV) } & \multirow[t]{2}{*}{ Angle (Deg) } & \multirow[t]{2}{*}{ Load MW } & \multirow[t]{2}{*}{ Load MVar } & \multirow[t]{2}{*}{ Gen MW } & \multirow[t]{2}{*}{ Gen MVar } & \multirow[t]{2}{*}{ s.shnts Mvar } \\
\hline NO & Name & & & & & & & & & \\
\hline 1 & 1 & 138 & 1.0000 & 138 & 0.01 & & & 243.29 & 48.73 & \\
\hline 2 & 2 & 138 & 0.96558 & 133.25 & -1.46 & 21.7 & 12.7 & 40 & 50 & \\
\hline 3 & 3 & 138 & 0.9115 & 125.787 & -3.67 & 94.2 & 19.0 & 0 & 0 & \\
\hline 4 & 4 & 138 & 0.92276 & 127.34 & -2.72 & 47.8 & 0.00 & & & \\
\hline 5 & 5 & 138 & 0.93304 & 128.76 & -2.25 & 7.6 & 1.6 & & & \\
\hline 6 & 6 & 138 & 0.90345 & 124.676 & -4.59 & 17.8 & 25.71 & 0 & 0 & \\
\hline 7 & 7 & 138 & 0.90974 & 125.544 & -4.06 & & & & & \\
\hline 8 & 8 & 138 & 0.90974 & 125.544 & -4.06 & & & 0 & 0 & \\
\hline 9 & 9 & 138 & 0.90309 & 124.627 & -4.78 & 29.5 & 16.6 & & & 0 \\
\hline 10 & 10 & 138 & 0.89828 & 123.962 & -4.78 & 9 & 5.8 & & & \\
\hline 11 & 11 & 138 & 0.89837 & 123.975 & -4.7 & 3.5 & 1.8 & & & \\
\hline 12 & 12 & 138 & 0.8919 & 123.028 & -4.8 & 6.1 & 1.6 & & & \\
\hline 13 & 13 & 138 & 0.88911 & 122.697 & -4.77 & 13.5 & 5.8 & & & \\
\hline 14 & 14 & 138 & 0.88218 & 121.741 & -5.01 & 14.9 & 5.0 & & & \\
\hline
\end{tabular}

Table 6: Bus records of the Modified standard IEEE 14 bus network with tier-1 compensation.

\begin{tabular}{|c|c|c|c|c|c|c|c|c|c|c|c|c|c|c|c|}
\hline \multicolumn{2}{|c|}{ Line Records } & $\begin{array}{l}\text { MW } \\
\text { From }\end{array}$ & MW To & Max MW & $\begin{array}{l}\text { Mvar } \\
\text { from }\end{array}$ & Mvar To & $\begin{array}{l}\text { Max } \\
\text { Mvar }\end{array}$ & $\begin{array}{l}\text { MVA } \\
\text { From }\end{array}$ & MVA To & $\begin{array}{l}\text { Max } \\
\text { MVA }\end{array}$ & $\begin{array}{l}\text { Amps } \\
\text { From }\end{array}$ & Amps To & $\begin{array}{l}\text { Max } \\
\text { Amps }\end{array}$ & MW loss & $\begin{array}{l}\text { Mvar } \\
\text { loss }\end{array}$ \\
\hline 1 & 2 & 161.1 & -156.037 & 161.15 & 22.3 & -11.831 & 22.333 & 162.7 & 156.49 & 162.69 & 677.898 & 680.23 & 680.23 & 5.11 & 10.5 \\
\hline 1 & 5 & 82.1 & -77.844 & 82.141 & 37.9 & -24.778 & 37.889 & 90.5 & 81.693 & 90.459 & 308.555 & 375.837 & 375.837 & 4.3 & 13.11 \\
\hline 2 & 3 & 78 & -74.856 & 78.019 & 29.9 & -19.244 & 29.875 & 83.5 & 77.019 & 83.544 & 354.832 & 350.199 & 350.199 & 3.44 & 10.63 \\
\hline 2 & 4 & 55.6 & -53.473 & 55.59 & 17.7 & -14.656 & 17.742 & 58.4 & 55.445 & 58.352 & 250.09 & 254.31 & 254.31 & 2.12 & 3.09 \\
\hline 2 & 5 & 40.7 & -39.561 & 40.278 & 15.4 & -14.892 & 15.393 & 43.5 & 42.271 & 43.54 & 186.856 & 191.631 & 191.631 & 1.17 & 0.5 \\
\hline 3 & 4 & -19.6 & 19.963 & 19.963 & 5.7 & -5.885 & 5.885 & 20.4 & 20.812 & 20.812 & 93.387 & 94.364 & 94.364 & 0.34 & 0.21 \\
\hline 4 & 5 & -63.7 & 64.349 & 64.349 & -6.9 & 8.912 & 8.912 & 64.1 & 64.963 & 64.963 & 290.858 & 290.868 & 290.868 & 0.65 & 2.04 \\
\hline 4 & 7 & 31.4 & -31.398 & 31.398 & 21.9 & -18.51 & 21.866 & 38.3 & 36.448 & 36.262 & 167.615 & 167.615 & 167.615 & 0.00 & 3.36 \\
\hline 4 & 9 & 18 & -18.016 & 18.016 & 13.3 & -10.317 & 13.256 & 22.4 & 20.761 & 22.367 & 96.176 & 96.176 & 96.176 & 0.00 & 2.94 \\
\hline 5 & 6 & 45.5 & -45.456 & 45.456 & 44.5 & -34.435 & 44.476 & 63.6 & 57.027 & 63.595 & 264.079 & 264.079 & 264.079 & 0.00 & 10.04 \\
\hline 6 & 11 & 4.2 & -4.222 & 4.244 & 1 & -0.905 & 0.951 & 4.3 & 4.317 & 4.349 & 20.122 & 20.12 & 20.12 & 0.02 & 0.05 \\
\hline 6 & 12 & 7.2 & -7.106 & 7.191 & 2.2 & -2.308 & 2.214 & 7.5 & 7.393 & 7.524 & 34.677 & 34.677 & 34.677 & 0.8 & 0.18 \\
\hline 6 & 13 & 16.2 & -15.985 & 16.244 & 6 & -5.558 & 6.03 & 17.3 & 16.923 & 17.309 & 79.633 & 79.633 & 79.633 & 0.24 & 0.47 \\
\hline 7 & 8 & 0 & 0 & 0 & 0 & 0 & 0 & 0 & 0 & 0 & 0 & 0 & 0 & 0 & 0 \\
\hline 7 & 9 & 31.4 & -31.398 & 31.398 & 19.7 & -17.98 & 19.745 & 37.1 & 36.982 & 37.091 & 167.615 & 167.615 & 167.615 & 0.00 & 1.77 \\
\hline 9 & 10 & 8.3 & -8.277 & 8.321 & 6.8 & -6.68 & 6.799 & 10.7 & 10.636 & 10.746 & 49.539 & 49.539 & 49.539 & 0.04 & 0.12 \\
\hline 9 & 14 & 11.7 & -11.434 & 11.686 & 5.4 & -4.821 & 5.356 & 12.9 & 12.409 & 12.855 & 58.85 & 58.85 & 58.85 & 0.25 & 0.53 \\
\hline 10 & 11 & -0.7 & 0.722 & 0.722 & 0.9 & -0.879 & 0.882 & 1.1 & 1.138 & 1.139 & 5.298 & 5.298 & 5.298 & 0.00 & 0.00 \\
\hline 12 & 13 & 1.00 & -1.033 & 1.007 & 0.4 & -0.437 & 0.44 & 1.1 & 1.094 & 1.099 & 5.15 & 5.15 & 5.15 & 0.00 & 0.00 \\
\hline 13 & 14 & 3.5 & -3.463 & 3.489 & 0.2 & -0.179 & 0.233 & 3.5 & 3.468 & 3.497 & 16.455 & 16.455 & 16.455 & 0.03 & 0.05 \\
\hline Total & & 511.9 & 494.215 & 681.092 & 244.3 & 185.113 & 260.278 & 742.9 & 706.48 & 744.193 & 3187.685 & 3212.958 & 3212.958 & 3212.958 & 59.17 \\
\hline
\end{tabular}

Table 7: Line Records of the the Modified standard IEEE 14 bus network with tier-1 compensation.

that the modified IEEE 14 bus system got overloaded and cannot accept this extra load (Table 5).

\section{Case 2: Application of tier-1 compensation to the modified standard IEEE 14 bus network}

The distributed capacitor technology applied on the transmission lines were used in this case to know how much the lines can be freed of their carriage even when the loads were operating. This was verified by placing capacitors on all the lines (interline action) with degree of compensation Ks allowed to operate by 0.7 or $70 \%$ of the original line reactance value (Table 6). The bus and line results were compared, from which the total active power loss reduced from 59.85 to 17.79 MW (70.28\% reduction) while the total reactive power loss reduced from 226.84 to 59.17 Mvar (73.92\% reduction). By this margin, the system's MVA loading was released from 1062.225 to 744.193 MVA
(29.94\% released) (Figure 8). This is resulted from the reduction in system's current from 5658.287 to 3212.958 Amps (43.94\% reduction) with all lines still operating within their normal limits. Bus voltages were also restored appreciably (Table 7).

Figures 9A-9D show the graphical plots of line numbers of the Modified standard IEEE 14 bus network (with tier-1 compensation) against the MW, Mvar, MVA loadings and bus p.u voltages with and without compensation.

The percentage reduction in MVA loading and savings determines how much the systems corridors have been expanded by the release of the embedded system capacity on which the system can be available for extra loadings (Table 8). 
Citation: Ezennaya SO, Ezechukwu OA, Anierobi CC, Akpe VA (2016) Expansion of Power System Corridors Using Tier-1 Technique for Reactive Power Compensation. J Electr Electron Syst 5: 163. doi:10.4172/2332-0796.1000163

\begin{tabular}{|c|c|c|c|c|c|c|}
\hline \multicolumn{2}{|c|}{} & & \multicolumn{2}{c|}{$\begin{array}{c}\text { The modified IEEE 14 } \\
\text { bus system (overloaded } \\
\text { system) }\end{array}$} & \multicolumn{2}{|c|}{$\begin{array}{c}\text { Use of tier-1 } \\
\text { compensator }\end{array}$} \\
\hline Bus records & Nom kV & PU Volt & Volt (kV) & PU Volt & Volt (kV) \\
\hline NO & Name & & & & & \\
\hline 1 & 1 & 138 & 1 & 138 & 1.0000 & 138 \\
\hline 2 & 2 & 138 & 0.82572 & 113.95 & 0.96558 & 133.25 \\
\hline 3 & 3 & 138 & 0.62455 & 86.188 & 0.9115 & 125.787 \\
\hline 4 & 4 & 138 & 0.59434 & 82.018 & 0.92276 & 127.34 \\
\hline 5 & 5 & 138 & 0.6584 & 90.859 & 0.93304 & 128.76 \\
\hline 6 & 6 & 138 & 0.48283 & 66.63 & 0.90345 & 124.676 \\
\hline 7 & 7 & 138 & 0.51624 & 71.241 & 0.90974 & 125.544 \\
\hline 8 & 8 & 138 & 0.51624 & 71.241 & 0.90974 & 12.544 \\
\hline 9 & 9 & 138 & 0.48187 & 66.497 & 0.90309 & 124.627 \\
\hline 10 & 10 & 138 & 0.4696 & 64.804 & 0.89828 & 123.962 \\
\hline 11 & 11 & 138 & 0.47045 & 64.923 & 0.89837 & 123.975 \\
\hline 12 & 12 & 138 & 0.45884 & 63.32 & 0.8919 & 123.082 \\
\hline 13 & 13 & 138 & 0.45279 & 62.486 & 0.88911 & 122.697 \\
\hline 14 & 14 & 138 & 0.43901 & 60.583 & 0.88218 & 121.741 \\
\hline
\end{tabular}

Table 8: Comparison of the modified IEEE 14 bus system voltage performance against operation results of the tier- 1 voltage result as a mean of validating the proposed compensation strategy for the bus records.

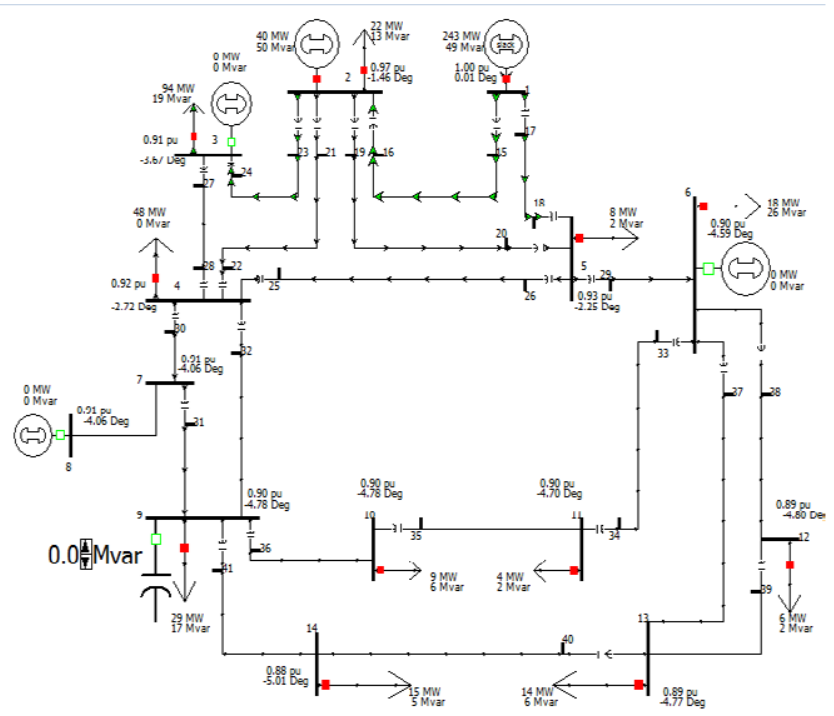

Figure 8: Modified standard IEEE 14 bus network with tier-1 compensation.

\section{Conclusion}

The use of DCC creates more loops in the transmission system by providing more active power routes without having to build new generating stations, new transmission stations or dealing with rightof-way issues. Application of the tier-1 compensation was able to accommodate the added load in the existing 14 bus system by releasing the system up to $29.94 \%$ MVAof its overloading which remarkably reduced the system's active losses by $70.28 \%$ and reactive losses by $73.92 \%$. Recommendations are made to simultaneously apply also the teir-2 and 3 to the network in other to ensure maximum restoration of the power (up to $100 \%$ restoration). This efficient control method can salvage the power system from total collapse and as well serves as a quick way to respond to consumers power satisfaction quest.

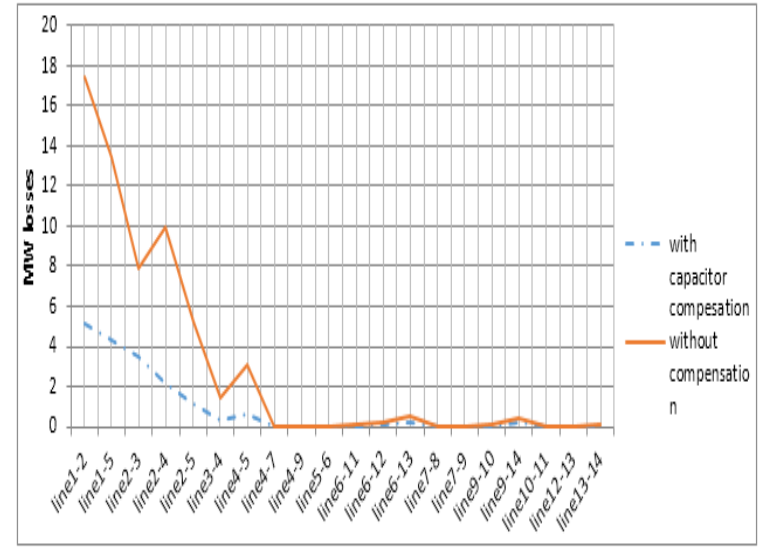

Figure 9A: Line number vs MW losses with and without capacitor compensation on the lines

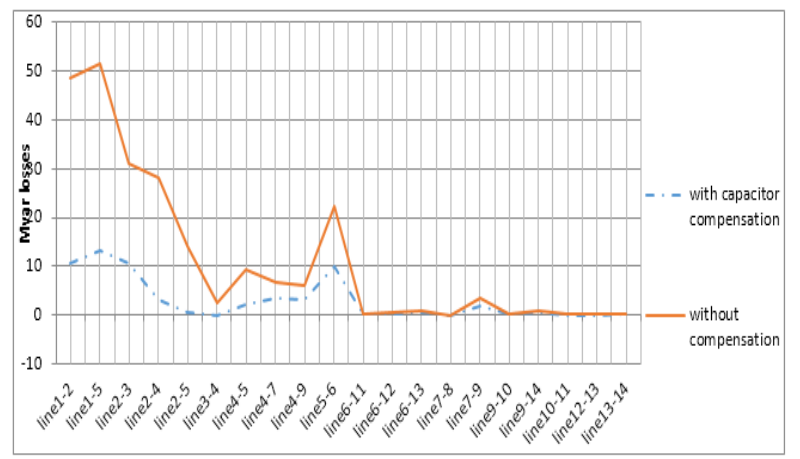

Figure 9B: Line Number vs Mvar Losses with and without capacitor compensation on the lines

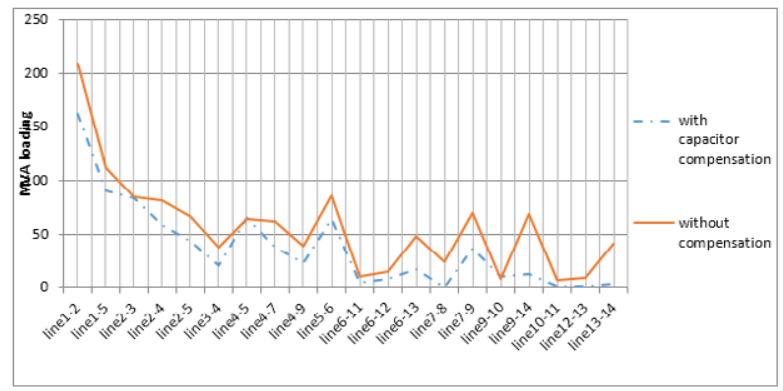

Figure 9C: Line numbers vs MVA Loadings with and without capacitor compensation on the lines

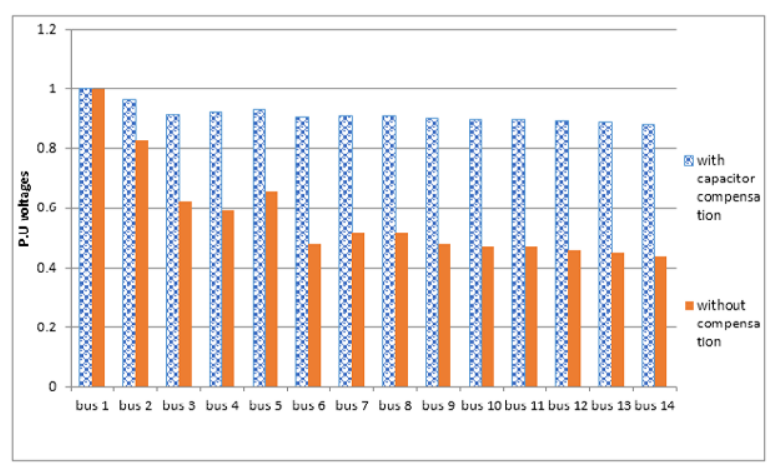

Figure 9D: Bus numbers vs p.u voltages with and without capacitor compensation on the lines

Figures 9A-D: Show the graphical plots of line numbers of the Modified standard IEEE 14 bus network (with tier-1 compensation) against the MW, Mvar, MVA loadings and bus p.u voltages with and without compensation. 
Citation: Ezennaya SO, Ezechukwu OA, Anierobi CC, Akpe VA (2016) Expansion of Power System Corridors Using Tier-1 Technique for Reactive Power Compensation. J Electr Electron Syst 5: 163. doi:10.4172/2332-0796.1000163

\section{References}

1. Nagesh HB, Puttas Wamy PS (2009) Power flow Model of Static VAR Compensator and Enhancement of Voltage Stability, IJAET.

2. Adepoju GA, Komolafe OA, Aborisade DO (2011) Power Flow Analysis of the Nigerian Transmission System Incorporating Facts Controllers. International Journal of Applied Science and Technology 1: 186-200.

3. Biswas MM, Das KK (2011) Voltage level Improvement by Using Static Var Compensator (SVC), GJRE J 11: 12-18.

4. Staniulis R (2001) Reactive Power Valuation, Lund University.

5. Rogers KM, Overbye TJ (2008) Some Applications of Distributed AC Transmission System (D-FACTS) devices in power systems.

6. Kiran IK, Laximi JA (2011) Shunt Versus Series Compensation in the improvement of power system performance, Int J Applied Eng Res, Dindigul.
7. Gruenbum R, Rasmussen J (2010) Series capacitors for increased power transmission capability of a $500 \mathrm{Kv}$ Grid intertile, ABB AB, Vasteras, Sweden.

8. Saadat H (1999) Power system Analysis, McGraw Hill Singapore.

9. Nagrath DP (2008) Power System Engineering, Tata McGraw Hill publishing company Ltd, New Delhi India.

10. Deng Y (2010) Reactive Power compensation of Transmission Lines, Concordia University.

11. Adebayo IG, Adejumobi IA, Olajire OS (2013) Power Flow Analysis and Voltage Stability Enhancement Using Thyristor Controlled Series Capacitor (TCSC) Facts Controller. IJEAT 2: 100-104.

12. Peter U (2013) Managerial Electrical Maintenance Report, Unpublished technical Report, Electrical Department, General Steel Mill. 